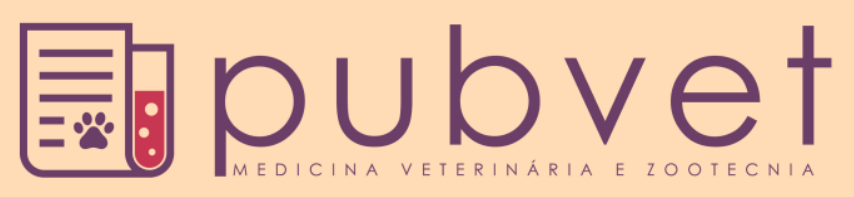

HTTP://DX.DOI.ORG/10.22256/PUBVET.V11N10.1002-1007

\title{
Epidemiologia do mastocitoma em cães em uma região do Mato Grosso do Sul
}

\author{
Paulo Henrique Braz ${ }^{*}$, Ana Eliza Coronel Janú Haniu², Alda Izabel de Souza ${ }^{3}$, Karine \\ Bonucielli Brum ${ }^{3}$
}

${ }^{1}$ Professor do curso de Medicina Veterinária do Centro Universitário da Grande Dourados, Departamento de Patologia Clínica. DouradosMS Brasil. E-mail: pauloh.braz@ hotmail.com

${ }^{2}$ Acadêmica de Medicina Veterinária do Centro Universitário da Grande Dourados, Departamento de Patologia Clínica. Dourados-MS Brasil. E-mail: anaelizza@gmail.com

${ }^{3}$ Professora do curso de Medicina Veterinária da Universidade Federal de Mato Grosso do Sul, Departamento de Patologia Animal. Campo Grande, MS.Brasil.E-mail: alda.izabel@ufms.br/karine.brum@ufms.br

*Autor para correspondência

RESUMO. O mastocitoma cutâneo é uma neoplasia observada frequentemente em cães. Esta doença é caracterizada pelo crescimento anormal e excessivo de mastócitos. Este estudo realizou o levantamento de dados de todos os arquivos de biopsia feito em cães no laboratório de Patologia clínica do Centro Universitário da Grande Dourados e da Universidade Anhaguera Uniderp no período entre janeiro de 2015 e janeiro de 2016. Foram selecionados 26 casos confirmados de mastocitoma canino, a partir da informação retiradas dos laudos foram avaliados fatores predisponentes como raça, sexo, idade e local das lesões neoplásicas. Em meio aos animais selecionados 46,2\% (12) eram fêmeas e $53,8 \%$ (14) machos. Com relação ao fator racial, 34,6\% (9) dos animais não possuem raça definida, 30,8\% (8) eram da raça Boxer, 11,5\% (3) eram da raça Pitbull, 7,7\% (2) da raça Labrador, 7,7\% (2) eram da raça Dachshund, 3,8\% (1) era da raça Poodle e 3,8\% (1) da raça Shnauzer. Concluiu se neste trabalho que a maioria dos cães acometidos por essa neoplasia eram sem raça definida. Quando considerado a raça observou se que os cães Boxer são os mais predispostos a esta neoplasia. Animais considerados idosos, com idade entre 9 e 13 anos são os mais acometidos. O mastocitoma canino não apresentou predisposição à doença quanto ao sexo e pôde-se verificar a maior frequência em relação à localização dos nódulos na parte do tronco e membros.

Palavras chave: Mastócitos, células redondas, tumores.

\section{Epidemiology of mastocytoma in dogs in a region of Mato Grosso do Sul Brazil}

ABSTRACT. Cutaneous mastocytoma is a neoplasm often seen in dogs. This disease is characterized by abnormal and excessive growth of mast cells. This study carried out the data collection of all biopsy files made in dogs in the clinical pathology laboratory of the University Center of Grande Dourados and Universidade Anhaguera Uniderp between January 2015 and January 2016. Twenty-six confirmed cases of mastocytoma From the information collected from the reports, predisposing factors such as race, sex, age and site of neoplastic lesions were evaluated. Among the selected animals, $46.2 \%$ (12) were females and $53.8 \%$ (14) males. Regarding the racial factor, 34.6\% (9) of the animals had no defined race, 30.8\% (8) were of the Boxer breed, $11.5 \%$ (3) were Pitbull breed, $7.7 \%$ ) Of the Labrador breed, $7.7 \%$ (2) were of the Dachshund breed, 3.8\% (1) was Poodle breed and $3.8 \%$ (1) of the Shnauzer breed. It was concluded in this study that the majority of the dogs affected by this neoplasia were undefined. When considered the breed it was observed that 
Boxer dogs are the most predisposed to this neoplasia. Animals considered elderly, aged between 9 and 13 years are the most affected. The canine mastocytoma showed no predisposition to the disease as to sex, and it was possible to verify the higher frequency in relation to the location of the nodules in the part of the trunk and limbs.

Keywords: Mast cells, round cells, tumors

\section{Epidemiología de mastocitoma en caninos en una región de Mato Grosso do Sul Brasil}

RESUMEN. El mastocitoma cutáneo es una neoplasia observada frecuentemente en perros. Esta enfermedad es caracterizada por el crecimiento anormal y excesivo de los mastocitos. Se realizó el levantamiento de datos de todos los archivos de biopsia realizados en perros en el laboratorio de Patología clínica del Centro Universitario de la Grande Dourados y de la Universidad Anhaguera Uniderp durante el período entre enero de 2015 a enero de 2016. Se seleccionaron 26 casos confirmados de mastocitoma A partir de la información retirada de los laudos se evaluaron factores predisponentes como raza, sexo, edad y lugar de las lesiones neoplásicas. En medio de los animales seleccionados el 46,2\% (12) eran hembras y el 53,8\% (14) machos. En cuanto al factor racial, el 34,6\% (9) de los animales no tienen raza definida, el 30,8\% (8) eran de la raza Boxer, el 11,5\% (3) eran de la raza Pitbull, el 7,7\% (2), raza Labrador, 7,7\% carrera (2) fueron Dachshund, 3,8\% (1) fue los caniche y de 3,8\% (1) carrera Shnauzer. Se concluyó que la mayoría de los perros acometidos por esa neoplasia eran sin raza definida. Cuando se consideró la raza se observó que los perros Boxer son los más predispuestos a esta neoplasia. Los animales con edad entre 9 y 13 años (considerados de edad avanzada), son los más afectados. El mastocitoma canino no presentó predisposición a la enfermedad en cuanto al sexo y se pudo verificar la mayor frecuencia en relación a la localización de los nódulos en la parte del tronco y miembros.

Palabras clave: Mastócitos, células redondas, tumores

\section{Introdução}

O mastocitoma canino é uma neoplasia cutânea de grande importância na clínica oncológica por se tratar de um tumor que possui comportamento biológico e sinais clínicos extremamente variáveis. Em muitos casos, surgem nódulos cutâneos simples ou múltiplos, que podem ser firmes ou flutuantes. Apresentam uma aparência granulomatosa ou ulcerativa, podendo ainda ser avermelhado e apresentar prurido concomitante (Bostock, 1986, Melo et al., 2013).

Essa neoplasia foi descrita em seres humanos e em muitas espécies domésticas, dentre as quais, é mais prevalente em caninos e felinos. $\mathrm{Na}$ espécie canina os mastocitomas são responsáveis por aproximadamente 7 a $20 \%$ de todas as neoplasias cutâneas malignas descritas (London and Seguin, 2003, Silva et al., 2014, Braz et al., 2016).

É importante ressaltar que o tumor de pele é a segunda neoplasia que mais acomete cães, sendo superada somente pelo tumor de mama. Ocorre em qualquer raça; porém se descreve uma maior incidência em cães da raça Boxer, Boston terrier,
Bullmastiff, Bulldog, Setter Inglês, Labrador, Golden Retriever, Teckel e Weimaraner (Fernandes et al., 2015, Meirelles et al., 2010, Withrow et al., 2014).

Estes tumores são diagnosticados com maior frequência em cães com idade média avançada; porém não se ignora sua ocorrência em animais jovens (Strefezzi et al., 2010). A etiologia dos mastocitomas não está comprovadamente definida e a verdadeira razão de sua elevada incidência ainda é desconhecida. As hipóteses incluem inflamação crônica, aplicação de substâncias irritantes na pele, infecção viral e alterações genéticas (Daleck et al., 2008).

A quantidade de tumores de pele diagnosticados, especialmente de mastocitomas, aumentou de forma gradativa nos últimos anos. Apesar de numerosos estudos sobre o mastocitoma, dados sobre esta neoplasia são escassos na região de Mato Grosso do Sul. Dessa forma, considera-se oportuno, revisar os aspectos epidemiológicos desta doença neste estado para aprimorar o diagnóstico do mastocitoma canino, 
auxiliando a conduta do médico veterinário frente a essa doença.

O objetivo do estudo foi determinar a frequência que representa o mastocitoma em relação aos atendimentos oferecidos no período do estudo e traçar um perfil epidemiológico da doença, incluindo raça, idade, sexo e cor de pelo dos animais acometidos por essa neoplasia.

\section{Material e Métodos}

Foi realizado um levantamento de 26 casos confirmados de mastocitoma canino no período de um ano. Os dados foram obtidos através da análise retrospectiva dos prontuários de atendimento clínico e dos laudos de exames citológicos e histopatológicos de cães atendidos nos Hospitais Veterinários do Centro Universitário da Grande Dourados (UNIGRAN), Dourados, MS e da Universidade Anhaguera Uniderp, Campo Grande, MS.

No decorrer da análise dos prontuários foram coletados dados como idade, sexo, raça, conformação e características de cada tumor. Foram inclusos no projeto somente os animais com diagnóstico confirmado por citologia ou histopatologia a fim de garantir a veracidade nas estatísticas.

Em cães que realizaram mais de uma biópsia para o mesmo tumor e obtiveram resultados positivos, como em casos de recidivas, o caso foi considerado somente uma vez. Os cães que apresentaram tumores em diferentes locais foram incluídos no levantamento mais de uma vez, dentro de sua categoria especifica, dessa forma há um maior número de tumores do que de cães.

As faixas etárias dos cães foram consideradas como segue: filhotes (até um ano de idade), adultos (de um a oito anos de idade) e idosos (acima de oito anos de idade). Quanto ao sexo, os cães foram classificados apenas como macho ou fêmea, independentemente de serem castrados ou inteiros.

\section{Resultados e Discussão}

O estudo retrospectivo dos casos de mastocitoma canino incluiu um total de 26 casos confirmados por citologia e ou histopatologia, sendo 12 cadelas fêmeas e 14 cães machos, de diversas raças, com idade entre 1 a 13 anos de idade. Dentre os 26 casos existentes, 17 casos foram obtidos do Hospital Veterinário da Anhaguera-Uniderp, Campo Grande, MS, enquanto que 9 casos foram advindos da Clínica Veterinária do Centro Universitário da Grande Dourados (Unigran) em Dourados, MS.

Dos 26 casos considerados, 34,6\% (9) dos animais não possuem raça definida (SRD), $30,8 \%$ (8) eram da raça Boxer, $11,5 \%$ (3) eram da raça Pitbull, 7,7\% (2) da raça Labrador, 7,7\% (2) eram da raça Dachshund, 3,8\% (1) eram da raça Poodle e $3,8 \%$ (1) da raça Shnauzer, conforme demonstrado na Figura 1.

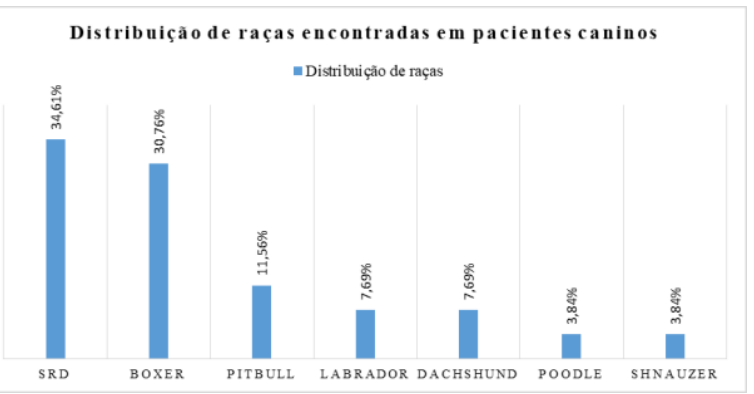

Figura 1. Distribuição da origem de raças encontrados nos pacientes caninos no período de janeiro de 2015 a janeiro de 2016 na clínica veterinária do Centro Universitário da Grande Dourados e Hospital Veterinário da Universidade Anhanguera-Uniderp.

Neste estudo observou se que os animais sem raça definida representam $34,61 \%$ (9) dos casos, equivalendo a maioria dos pacientes atendidos no período analisado. Estes dados não comprovam que os animais sem raça são mais acometidos que os animais de raças específica e sim que são os mais frequentes na rotina veterinária (Gough and Thomas, 2011). Provavelmente isso se deva ao número expressivo de exemplares SRD na população canina da região.

Dentre os animais de raça definida, os que apresentaram maior ocorrência de mastocitoma foram animais da raça Boxer 30,8\% (8) e Pitbull $11,5 \%$ (3), com relação a esta incidência os resultados corroboram os achados de vários autores que citam a raça Boxer como a mais predisposta a esta neoplasia. Diversos autores afirmam que raças braquiocefálicas, como Boxer, Boston terrier, Bullmastiff e Bulldog inglês e a faixa etária por volta dos oito anos são os fatores que mais predispõem a essa neoplasia (Furlani et al., 2008, Nelson and Couto, 2015, Palma et al., 2009). Welle et al. (2008) confirmaram a maior incidência de mastocitoma nestas raças e referiram se a predisposição em raças de grande porte a terem maior probabilidade de desenvolverem mastocitoma. 
Neste estudo obteve-se o mastocitoma presente em 7,7\% (2) dos Labradores e 7,7\% (2) dos Dachshund. Estas raças são citadas pela literatura como predispostas a este tumor, além de Buldogue e animais mestiços (Costa-Casagrande et al., 2008, Welle et al., 2008, Strefezzi et al., 2010, Costa-Poggiani et al., 2012). Outras raças como poodle 3,8\% (1) e Shnauzer 3,8\% (1) não são indicadas na literatura como predispostas ao mastocitoma.

Dos cães avaliados, 46,2\% (12) eram fêmeas enquanto $53,8 \%$ (14) eram machos. Não há correlação entre o sexo e a incidência do tumor, embora seja observada uma pequena tendência aos cães machos, muito embora não haja um consenso quanto à predisposição sexual (Simoes et al., 1994, Costa-Casagrande et al., 2008, O'connell and Thomson, 2013).

Quando levado em conta a idade dos animais, não houve casos inseridos na categoria de filhotes. Já, 42,3\% (11) foram incluídos como cães adultos, com idade variando entre 1 e 8 anos, 50,0\% (13) dos animais foram incluídos como idosos, acima de 8 anos de idade. Em 7,7\% (2) dos casos os animais não tiveram suas idades informadas no prontuário, conforme demonstrado na Figura 2.

A idade dos animais com aparecimento da lesão tumoral mais observada foi entre 9 e 13 anos. Segundo Maxie and Jubb (2007) o mastocitoma é uma neoplasia maligna que agride cães em qualquer faixa etária, podendo variar de três semanas até 19 anos de idade, mas acometem principalmente animais com a idade média de nove anos.

\section{Idade dos animais acometidos por mastocitoma}

- Filhotes (0) - Adultos (11) - Idosos (13) - Idade não Irformada (2)

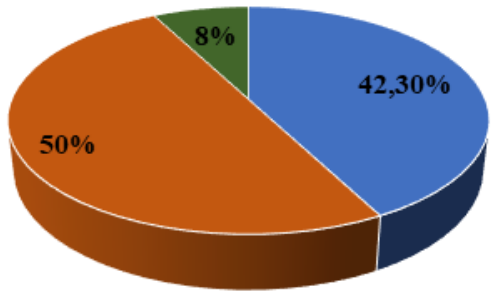

Figura 2. Faixa etária dos pacientes caninos com mastocitoma atendidos no período de janeiro de 2015 a janeiro de 2016 na Clínica Veterinária do Centro Universitário da Grande Dourados e no Hospital Veterinário da Universidade Anhanguera Uniderp.

Quanto à localização anatômica, os 30 nódulos encontrados tiveram sua distribuição informada na seguinte ordem decrescente de frequência: os tumores na região do tronco (regiões torácica, axilar, abdominal, mamária, inguinal, lombar e cauda) apresentaram maior prevalência, representado por $46,7 \%$ (14) dos casos, seguido pelos tumores nos membros $30,0 \%$ (9) e por $13,3 \%$ (4) em região perianal (escrotal, peniana e vulvar). Os locais de menor inclusão tumoral foram na região de cabeça e pescoço, com apenas $10 \%$ (3) dos animais acometidos (Figura 3).

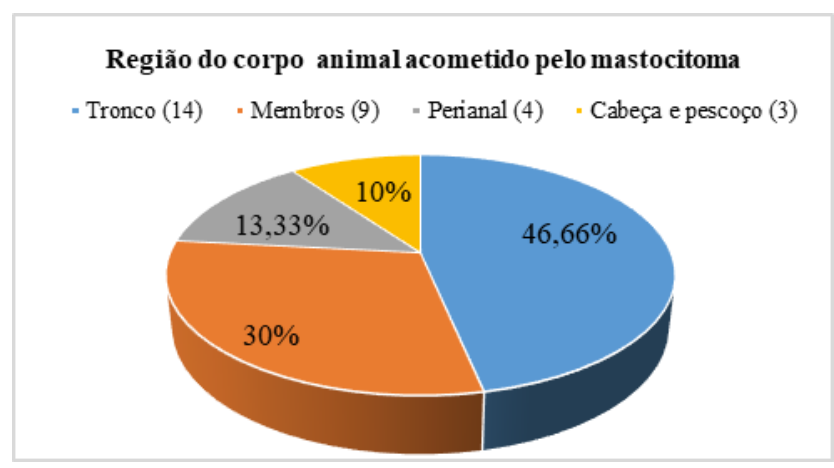

Figura 3. Localização anatômica dos nódulos encontrados nos pacientes atendidos no período de janeiro de 2015 a janeiro de 2016 na Clínica Veterinária do Centro Universitário da Grande Dourados e no Hospital Veterinário da Universidade Anhanguera Uniderp.

Estes dados são corroborados por vários autores que citam a localização do tronco e as regiões perineal, genital e inguinal responsáveis por $50 \%$ dos mastócitos cutâneos enquanto que $40 \%$ são encontrados nos membros e $10 \%$ na cabeça e no pescoço. (O'Keefe, 1990, Palma et al., $\underline{2009)}$.

Sabe se que mastocitoma pode acometer qualquer região corpórea e diferentemente dos dados encontrados em nosso estudo Dobson and Scase (2007) verificaram maior acometimento em membros, região inguinal e prepucial; estes autores ainda citam que mastocitomas localizados em regiões muco cutâneas e na região inguinal exibem um comportamento mais agressivo, apesar de vários estudos não demonstrarem concordância em relação a este assunto (Welle et al., 2008, Dobson and Scase, 2007).

Em muitos estudos retrospectivos dados incompletos nos prontuários dos animais são informações que limitam estudos mais aprofundados. Em nosso trabalho, não conseguimos relacionar a pelagem animal a uma frequência em relação a esta doença, pois não existem dados consistentes nos prontuários acerca da pelagem dos animais, assim este dado não pode ser mensurado, por isso devemos ressaltar que o veterinário tem que estabelecer um tempo de seu 
exame para este processo pois o registro de informações acerca do paciente no prontuário é o principal meio de avaliar a assistência prestada e estabelece uma forma de legitimar o trabalho daquele que o executou, além de servir como um instrumento útil nas ações de ensino e pesquisa.

\section{Conclusão}

Considerando o grupo de animais estudados e as condições propostas neste trabalho podemos inferir que o mastocitoma canino está associado a cães considerados idoso, na faixa etária de 9 a 13 anos. A predisposição ao mastocitoma é comprovada em raças braquiocefalicas como Boxer e Bulldogue, além de outras como Boston terrier, Bullmastiff, Labrador e Dachshund, necessitando de atenção especial por parte do clinico quanto a suspeita de algum tumor nestas raças. A incidência desta neoplasia não tem correlação com o sexo animal e a maioria dos mastocitomas é encontrada na região do tronco e membros.

A avaliação contínua dos aspectos epidemiológicos associada ao diagnóstico de mastocitoma pode contribuir para a identificação de possíveis fatores de risco e desenvolvimento desta neoplasia que é frequente na rotina veterinária.

\section{Referências Bibliográficas}

Bostock, D. E. 1986. Neoplasms of the skin and subcutaneous tissues in dogs and cats. British Veterinary Journal, 142, 1-19.

Braz, P. H., Brum, K. B., Souza, A. I. \& Abdo, M. A. 2016. Comparação entre a citopatologia por biopsia com agulha fina e a histopatologia no diagnóstico das neoplasias cutâneas e subcutâneas de cães. Pesquisa Veterinária Brasileira, 36, 197-203.

Costa-Casagrande, T. A., Elias, D. S., Melo, S. R. \& Matera, J. M. 2008. Estudo retrospectivo do mastocitoma canino no serviço de cirurgia de pequenos animais-Hospital Veterinário da Faculdade de Medicina Veterinária e Zootecnia da Universidade de São Paulo. Archives of Veterinary Science, 13, 176-183.

Costa-Poggiani, S. S., Terra, E. M., Neto, R. T., Costa, M. T. \& Amorim, R. L. 2012. Canine cutaneous mast cell tumor: Biologic behavior and its correlation with prognostic indicators. Open Journal of Veterinary Medicine, 2, 255261.
Daleck, C. R., De Nardi, A. B., Rodigheri, S. M. \& Motta, F. R. 2008. Neoplasia do sistema urinário. Roca, São Paulo.

Dobson, J. M. \& Scase, T. J. 2007. Advances in the diagnosis and management of cutaneous mast cell tumours in dogs. Journal of Small Animal Practice, 48, 424-431.

Fernandes, C. C., Medeiros, A. A., Magalhães, G. M., Szabó, M. P. J., Queiroz, R. P., Silva, M. V. A. \& Soares, N. P. 2015. Frequência de neoplasias cutâneas em cães atendidos no hospital veterinário da Universidade Federal de Uberlândia durante os anos 2000 a 2010. Bioscience Journal, 31, 541-548.

Furlani, J. M., Daleck, C. R., Vicenti, F. A. M., De Nardi, A. B., Pereira, G. T., Santana, Á. E., Eurides, D. \& da Silva, L. A. F. 2008. Mastocitoma canino: estudo retrospectivo. Ciência Animal Brasileira, 9, 242-250.

Gough, A. \& Thomas, A. 2011. Breed predispositions to disease in dogs and cats. Oxford: Blackwell Publishing, London.

London, C. A. \& Seguin, B. 2003. Mast cell tumors in the dog. Veterinary Clinics of North America: Small Animal Practice, 33, 473-489.

Maxie, M. G. \& Jubb, K. 2007. Palmer's pathology of domestic animals. Philadelphia, 5, 523-653.

Meirelles, A. E. W. B., Oliveira, E. C., Rodrigues, B. Á., Costa, G. R., Sonne, L., Tesser, E. S. \& Driemeier, D. 2010. Prevalência de neoplasmas cutâneos em cães da Região Metropolitana de Porto Alegre, RS: 1.017 casos (2002-2007). Pesquisa Veterinaria Brasileira, 30, 968-973.

Melo, I. H. S., Magalhães, G. M., Alves, C. E. F. \& Calazans, S. G. 2013. Mastocitoma cutâneo em cães: uma breve revisão. Revista de Educação Continuada em Medicina Veterinária e Zootecnia, 11, 38-43.

Nelson, R. W. \& Couto, C. G. 2015. Medicina interna de pequenos animais. Elsevier Editora, Amsterdan.

O'connell, K. \& Thomson, M. 2013. Evaluation of prognostic indicators in dogs with multiple, simultaneously occurring cutaneous mast cell tumours: 63 cases. Veterinary and Comparative Oncology, 11, 51-62.

O'Keefe, D. A. 1990. Canine mast cell tumors. Veterinary Clinics of North America: Small Animal Practice, 20, 1105-1115.

Palma, H. E., Martins, D. B., Basso, P. C., Amaral, A. S. d., Teixeira, L. V. \& Lopes, S. T. d. A. 
2009. Mastocitoma cutâneo canino: revisão. Medvep - Revista Científica de Medicina Veterinária - Pequenos Animais e Animais de Estimação, 7, 523-528.

Silva, A. L. D. A., Querioz, R. P., Szabó, M. P. J. \& Medeiros, A. A. 2014. Grau de malignidade do mastocitoma cutâneo canino quanto a localização segundo as classificações de Patnaik et al.(1984) e Kiupel et al.(2011). Revista Brasileira de Ciência Veterinária, 21, 183-187.

Simoes, J. P. C., Schoning, P. \& Butine, M. 1994. Prognosis of canine mast cell tumors: a comparison of three methods. Veterinary Pathology, 31, 637-647.

Strefezzi, R. F., Kleeb, S. R., Xavier, J. G. \& Dias, J. L. C. 2010. Avaliação da proliferação celular como indicador prognóstico para mastocitomas cutâneos caninos. Pesquisa Veterinária Brasileira, 30, 559-565.
Welle, M. M., Bley, C. R., Howard, J. \& Rüfenacht, S. 2008. Canine mast cell tumours: a review of the pathogenesis, clinical features, pathology and treatment. Veterinary Dermatology, 19, 321-339.

Withrow, S. J., Page, R. \& Vail, D. M. 2014. Withrow and MacEwen's small animal clinical oncology. Elsevier Health Sciences, St. Louis.

\section{Article History:}

Received 5 June 2017

Accepted 17 July 2017

Available online 21 August 2017

License information: This is an open-access article distributed under the terms of the Creative Commons Attribution License 4.0, which permits unrestricted use, distribution, and reproduction in any medium, provided the original work is properly cited. 